\title{
Plasma alkylresorcinol concentrations, biomarkers of whole-grain wheat and rye intake, in the European Prospective Investigation into Cancer and Nutrition (EPIC) cohort
}

Cecilie Kyrø ${ }^{1 *}$, Anja Olsen ${ }^{1}$, H. B(as). Bueno-de-Mesquita ${ }^{2,3}$, Guri Skeie ${ }^{4}$, Steffen Loft ${ }^{5}$, Per Åman ${ }^{6}$, Max Leenders ${ }^{3}$, Vincent K. Dik ${ }^{3}$, Peter D. Siersema ${ }^{3}$, Tobias Pischon ${ }^{7}$, Jane Christensen ${ }^{1}$, Kim Overvad ${ }^{8}$, Marie-Christine Boutron-Ruault ${ }^{9,10,11}$, Guy Fagherazzi ${ }^{9,10,11}$, Vanessa Cottet ${ }^{9,10,11}$, Tilman Kühn ${ }^{12}$, Jenny Chang-Claude ${ }^{12}$, Heiner Boeing ${ }^{13}$, Antonia Trichopoulou ${ }^{14,15}$, Androniki Naska $^{14,15}$, Despoina Oikonomidou ${ }^{14}$, Giovanna Masala ${ }^{16}$, Valeria Pala ${ }^{17}$, Rosario Tumino ${ }^{18}$, Paolo Vineis ${ }^{19}$, Amalia Mattiello ${ }^{20}$, Petra H. Peeters ${ }^{21}$, Toril Bakken ${ }^{4}$, Elisabete Weiderpass ${ }^{4,22,23,24}$, Lene Angell Åsli ${ }^{4}$, Soledad Sánchez ${ }^{25}$, Paula Jakszyn ${ }^{26}$, María-José Sánchez ${ }^{27,28}$, Pilar Amiano ${ }^{29}$, José María Huerta ${ }^{28,30}$, Aurelio Barricarte ${ }^{28,31}$, Ingrid Ljuslinder ${ }^{32}$, Richard Palmqvist ${ }^{33}$, Kay-Tee Khaw ${ }^{34}$, Nick Wareham ${ }^{34,35}$, Timothy J. Key ${ }^{36}$, Ruth C. Travis ${ }^{36}$, Nadia Slimani ${ }^{37}$, Heinz Freisling ${ }^{37}$, Pietro Ferrari ${ }^{37}$, Marc J. Gunter ${ }^{38}$, Neil Murphy ${ }^{38}$, Elio Riboli ${ }^{38}$, Anne Tjønneland ${ }^{1}$ and Rikard Landberg ${ }^{6}$

${ }^{1}$ Danish Cancer Society Research Center, Strandboulevarden 49, Copenhagen Ø 2100, Denmark

${ }^{2}$ National Institute for Public Health and the Environment (RIVM), Bilthoven, The Netherlands

${ }^{3}$ Department of Gastroenterology and Hepatology, University Medical Center Utrecht, Utrecht, The Netherlands

${ }^{4}$ Department of Community Medicine, University of Tromsø, Tromsø, Norway

${ }^{5}$ Section of Environmental Health, Department of Public Health, Faculty of Health Sciences, University of Copenhagen,

Copenhagen, Denmark

${ }^{6}$ Department of Food Science, BioCenter, Swedish University of Agricultural Sciences, Uppsala, Sweden

${ }^{7}$ Molecular Epidemiology Group, Max-Delbrück-Center for Molecular Medicine Berlin-Buch, Berlin, Germany

${ }^{8}$ Section for Epidemiology, Department of Public Health, Aarhus University, Aarbus, Denmark

${ }^{9}$ INSERM, Centre for Research in Epidemiology and Population Health (CESP), Villejuif Cedex, France

${ }^{10}$ Université Paris-Sud, Villejuif, France

${ }^{11}$ Institut Gustave Roussy, Villejuif, France

${ }^{12}$ Division of Cancer Epidemiology, German Cancer Research Center, DKFZ, Heidelberg, Germany

${ }^{13}$ Department of Epidemiology, German Institute of Human Nutrition Potsdam-Rehbruecke, Nuthetal, Germany

${ }^{14}$ Hellenic Health Foundation, Athens, Greece

${ }^{15}$ Department of Hygiene, Epidemiology and Medical Statistics, WHO Collaborating Center for Food and Nutrition Policies, University of Athens Medical School, Athens, Greece

${ }^{16}$ Molecular and Nutritional Epidemiology Unit, Cancer Research and Prevention Institute - ISPO, Florence, Italy

${ }^{17}$ Epidemiology and Prevention Unit, Fondazione IRCCS Istituto Nazionale dei Tumori, Milan, Italy

${ }^{18}$ Cancer Registry and Histopathology Unit, "Civile - M.P. Arezzo" Hospital, ASP Ragusa, Italy

${ }^{19}$ MRC/HPA Centre for Environment and Health, School of Public Health, Imperial College London, London, UK

${ }^{20}$ Dipartimento di Medicina Clinica e Chirurgia, Federico II University, Naples, Italy

${ }^{21}$ Department of Epidemiology, Julius Center for Health Sciences and Primary Care, University Medical Center Utrecht,

Utrecht, The Netherlands

${ }^{22}$ Department of Research, Cancer Registry of Norway, Oslo, Norway

${ }^{23}$ Department of Medical Epidemiology and Biostatistics, Karolinska Institutet, Stockholm, Sweden

${ }^{24}$ Samfundet Folkhälsan, Helsinki, Finland

${ }^{25}$ Public Health Directorate, Asturias, Spain

${ }^{26}$ Unit of Nutrition, Environment and Cancer, Cancer Epidemiology Research Programme, Catalan Institute of Oncology, Barcelona, Spain

Abbreviations: AR, alkylresorcinols; EPIC, European Prospective Investigation into Cancer and Nutrition.

*Corresponding author: C. Kyrø, fax + 45 35271811, email ceciliek@cancer.dk 
${ }^{27}$ Andalusian School of Public Health, Granada, Spain

${ }^{28}$ CIBER EPidemiología y Salud Pública (CIBERESP), Madrid, Spain

${ }^{29}$ Public Health Division of Guipuzkoa, Basque Regional Health Department, San Sebastian, Spain

${ }^{30}$ Department of Epidemiology, Murcia Regional Health Council, Murcia, Spain

${ }^{31}$ Navarre Public Health Institute, Pamplona, Spain

${ }^{32}$ Department of Radiation Sciences, Oncology, Umeå University, Umeå, Sweden

${ }^{33}$ Department of Medical Biosciences, Pathology, Umeå University, Umeà, Sweden

${ }^{34}$ Department of Public Health and Primary Care, University of Cambridge, Cambridge, UK

${ }^{35}$ Medical Research Council Epidemiology Unit, University of Cambridge, Cambridge, UK

${ }^{36}$ Cancer Epidemiology Unit, University of Oxford, Oxford, UK

${ }^{37}$ International Agency for Research on Cancer (IARC-WHO), Lyon, France

${ }^{38}$ Department of Epidemiology and Biostatistics, School of Public Health, Imperial College London, London, UK

(Submitted 2 July 2013 - Final revision received 25 November 2013 - Accepted 13 December 2013 - First published online 13 February 2014)

\section{Abstract}

Whole-grain intake has been reported to be associated with a lower risk of several lifestyle-related diseases such as type 2 diabetes, CVD and some types of cancers. As measurement errors in self-reported whole-grain intake assessments can be substantial, dietary biomarkers are relevant to be used as complementary tools for dietary intake assessment. Alkylresorcinols (AR) are phenolic lipids found almost exclusively in whole-grain wheat and rye products among the commonly consumed foods and are considered as valid biomarkers of the intake of these products. In the present study, we analysed the plasma concentrations of five AR homologues in 2845 participants from ten European countries from a nested case-control study in the European Prospective Investigation into Cancer and Nutrition. High concentrations of plasma total AR were found in participants from Scandinavia and Central Europe and lower concentrations in those from the Mediterranean countries. The geometric mean plasma total AR concentrations were between 35 and $41 \mathrm{nmol} / 1 \mathrm{in}$ samples drawn from fasting participants in the Central European and Scandinavian countries and below $23 \mathrm{nmol} / \mathrm{l}$ in those of participants from the Mediterranean countries. The whole-grain source (wheat or rye) could be determined using the ratio of two of the homologues. The main source was wheat in Greece, Italy, the Netherlands and the UK, whereas rye was also consumed in considerable amounts in Germany, Denmark and Sweden. The present study demonstrates a considerable variation in the plasma concentrations of total AR and concentrations of AR homologues across ten European countries, reflecting both quantitative and qualitative differences in the intake of whole-grain wheat and rye.

\section{Key words: Whole grains: Alkylresorcinols: Biomarkers}

Whole-grain intake appears to play an important role in the prevention of major lifestyle diseases such as type 2 diabetes, CVD and some types of cancers ${ }^{(1,2)}$. In 2011, the World Cancer Research Fund/American Institute for Cancer Research upgraded the evidence for an inverse association between dietary fibre intake and colorectal cancer risk from 'probable' to 'convincing'(3). The association between dietary fibre intake and colorectal cancer risk seems in particular to be strong for cereal fibre and whole grains ${ }^{(4)}$. Evidence for an association between whole-grain intake and some cancers, e.g. colorectal cancer, is less strong than that for dietary fibre intake, because few studies have provided accurate information on whole-grain intake ${ }^{(3-5)}$.

The measurement of dietary intake in general is challenging $^{(6)}$, but that of whole-grain intake might be particularly prone to measurement errors because there is a large variation in whole-grain content in different products and consumers may have difficulty in recognising whole-grain products among other products ${ }^{(7)}$. These together with the lack of a common definition of whole-grain products make comparison of whole-grain intake between studies and countries difficult ${ }^{(8)}$.
Alkylresorcinols (AR) have been evaluated as valid concentration biomarkers of whole-grain wheat and rye intake ${ }^{(9)}$. AR are phenolic lipids found in the bran fraction of rye, wheat and barley. However, the amount of AR found in barley is very small, and barley is not consumed in high amounts in Europe. Therefore, AR are almost exclusively present in whole-grain wheat and rye products or in products with added wheat or rye bran, and only traces or low quantities are found in refined products ${ }^{(10)}$. AR are generally not affected by food processing, are absorbed in the small intestine ${ }^{(11)}$ and can be measured in blood plasma. Intervention studies have shown that plasma AR concentrations are significantly affected by the dietary intake of whole-grain wheat and rye ${ }^{(12)}$. In observational studies, a moderate correlation $(r 0.25-0.54)$ has been found between plasma concentrations of AR and intake of wholegrain foods estimated from $\mathrm{FFQ}^{(13,14)}$. Despite a relatively short elimination half-life of approximately $5 \mathrm{~h}^{(15)}$, AR concentrations in a single fasting sample reflect the long-term concentrations ( 1 month to 4 years) relatively well in populations with a frequent and stable intake ${ }^{(16,17)}$. There are five AR homologues in wheat and rye: $\mathrm{C} 17: 0 ; \mathrm{C} 19: 0 ; \mathrm{C} 21: 0 ; \mathrm{C} 23: 0$; $\mathrm{C} 25: 0$. The ratio between two of the homologues 
(C17:0/C21:0) can be used to determine whether the wholegrain diet is mainly dominated by wheat or rye ${ }^{(18)}$. Ratios lower than 0.2 in plasma indicate an intake dominated by wheat and higher ratios indicate that whole-grain rye is also consumed $^{(9,19,20)}$

Information on whole-grain intake in Europe is scarce, and due to the different definitions of whole grains and the variation in whole-grain products consumed in the different countries, comparison of whole-grain intake is difficult. Information on AR concentrations in different populations might be useful to examine relative differences in whole-grain intake between countries, as well as serve as an objective ranking tool for whole-grain wheat and rye intake in relation to disease endpoints in observational studies. However, data on AR concentrations and AR C17:0/C21:0 ratios from observational studies representing different countries are limited.

Therefore, the aim of the present study was to evaluate the group-level variability in total AR concentrations and concentrations of the five AR homologues (C17:0, C19:0, C21:0, C23:0 and C25:0) as well as assess the C17:0/C21:0 ratio in plasma samples collected from participants from ten Western European countries using data from the European Prospective Investigation into Cancer and Nutrition (EPIC)

\section{Subjects and methods}

\section{Study population and data collection}

The EPIC cohort is a large multicentre cohort study of more than half a million European participants. The cohort consists of participants from twenty-three centres in Denmark, France, Germany, Greece, Italy, the Netherlands, Norway, Spain, Sweden and the UK.

Most of the participants were recruited from the general population, except for the French cohort (a teacher's organisation health insurance programme), the Italian (Florence and Turin) and Spanish cohorts (mostly blood donors), the Utrecht (the Netherlands) cohort (women attending mammographic screening programmes), and part of the Oxford (UK) cohort. The EPIC-Norfolk and EPIC-Oxford cohorts are the two UK cohorts included in the EPIC cohort. The EPIC-Norfolk cohort represents the general population, while the EPIC-Oxford cohort comprises participants from the general population as well as vegetarians and healthconscious people. In the present study, only one of the Swedish cohorts was included (Umeå), as biological samples were not available from the Malmö cohort. At baseline (1993-8), lifestyle questionnaire, dietary questionnaires and anthropometric data were collected from the participants ${ }^{(21)}$.

Biological samples, including plasma samples, were collected at baseline from 385747 of the 519978 EPIC participants and stored for later use. Samples from all centres were processed and aliquoted at the local study centres. After that, samples from Denmark and Sweden were stored in tubes at $-150^{\circ} \mathrm{C}$ under $\mathrm{N}_{2}$ vapour in a biobank in Copenhagen, Denmark, or in $-80^{\circ} \mathrm{C}$ freezers in Umeå, Sweden. Samples from the other eight countries were stored in heat-sealed straws at $-196^{\circ} \mathrm{C}$ under liquid $\mathrm{N}_{2}$ at the International Agency for Research on Cancer (IARC) biobank in Lyon, France ${ }^{(21)}$. The study was approved by the Ethical Review Board of the IARC and the ethical committees of the participating centres. All participants provided informed consent, and procedures were in line with the Declaration of Helsinki.

A total of 3100 men and women (1550 colorectal cancer cases and 1550 matched controls) from a nested case-control study on AR in relation to colorectal cancer risk were included in the present study. Only plasma samples from 3059 participants were retrieved, as plasma samples from forty-one participants were not available in the biobanks. AR concentrations were successfully analysed in only 2849 samples of the initial 3100 samples, mostly due to missing samples or to insufficient volume rather than due to laboratory errors. When the blood samples were drawn, $28 \%$ of the participants were fasting ( $>6 \mathrm{~h}$ since the last meal).

\section{Estimation of dietary fibre intake}

Information on 'habitual' dietary intake was collected from each participant with validated country-specific dietary questionnaires $^{(21)}$. Cereal fibre intake was estimated using the standardised EPIC Nutrient Database ${ }^{(22)}$. In the EPIC Nutrient Database, dietary fibre intake definitions are based on the gravimetric method developed by the Association of Official Agricultural Chemists ${ }^{(23)}$ for all countries, except for the UK and Greece, where the Englyst method is used ${ }^{(24)}$.

\section{Laboratory analyses}

During a period of 1 year, the concentrations of plasma AR homologues (C17:0, C19:0, C21:0, C23:0 and C25:0) were determined using a $\mathrm{GC}-\mathrm{MS}$ method in which molecular ions were used for quantification in a single-ion monitoring mode ${ }^{(25)}$. For each participant, $200 \mu \mathrm{l}$ of plasma were used. The samples were randomised, but matched case-control pairs were analysed together. In each batch, four quality control samples were included. The within-day and between-day precision values expressed as CV were 11 and $22 \%$, respectively. Plasma concentrations of the individual homologues (C17:0, C19:0, C21:0, C23:0 and C25:0) and their sum (plasma total AR concentrations) were used in the statistical analyses.

\section{Determination of the alkylresorcinol C17:0/C21:0 ratio}

The AR C17:0/C21:0 ratio may indicate whether the diet is dominated by whole-grain wheat or rye. Among the cereals, the ratio is typically $0 \cdot 1$ in common wheat, $0 \cdot 01$ in durum wheat and 1.0 in rye ${ }^{(18)}$. In human plasma samples, factors other than dietary intake also affect the $\mathrm{C} 17: 0 / \mathrm{C} 21: 0$ ratio to some extent. Under controlled intervention conditions, the ratio is typically $0 \cdot 1-0 \cdot 2$ and $0 \cdot 6-0 \cdot 8$ after whole-grain wheat and rye consumption, respectively ${ }^{(12,26)}$. A low ratio $(<0 \cdot 2)$ is indicative of a wheat-dominated diet and a higher ratio is indicative of a rye-dominated diet. 


\section{Exclusions}

In total, 2849 samples were successfully analysed for AR concentrations, and four of these samples were excluded because of missing data on covariates, leaving 2845 samples to be included in the statistical analyses.

\section{Statistical analyses}

The distribution of AR and AR homologues was skewed and was, therefore, normalised by $\log$ transformation (natural logarithm). Mean values for total AR and AR homologues on the logarithmic scale were calculated, and geometric mean values and standard deviations were obtained by back transformation.

In all country-specific analyses, the UK cohort was included as two separate groups (UK general population and UK 'health conscious'), because part of the EPIC cohort in Oxford was over-represented by health-conscious people and vegetarians, and thereby it might have whole-grain intake different from that of the UK cohort representing the general population (EPIC-Norfolk). Therefore, the healthconscious part of the Oxford cohort was grouped alone and the remainder of the Oxford cohort was merged with the Norfolk cohort to form the group 'UK general population'.

Correlations between plasma total AR concentrations and cereal fibre intake were investigated using Pearson's correlations, both crude and partial Pearson's correlations adjusted for sex and fasting status (no: $<3 \mathrm{~h}$, in between: $3-6 \mathrm{~h}$, and yes: $>6 \mathrm{~h}$ ).

The $t$ test was used to test the null hypothesis of no difference in plasma total AR concentrations between cases and controls. As no difference was found $(P=0.59)$, it was decided to include both cases and controls in the study. The $t$ test was also used to test whether plasma total AR concentrations and the ratio between two of the AR homologues (C17:0/C21:0) differed by sex and by fasting status. Differences in mean values for countries were tested using the $F$ test.

The analyses were carried out using the SAS ${ }^{\circledR}$ software (version 9.3; SAS Institute, Inc.). The UNIVARIATE and FREQ procedures were used for descriptive statistics. The TTEST procedure was used for the $t$ test. The CORR (Pearson) procedure was used for the correlation analyses. $P$ values (two-sided) lower than 0.05 were considered to be statistically significant.

\section{Results}

In total, 2845 participants from ten European countries were included in the present study, with the largest group being from Denmark ( $n$ 732) and the smallest from Norway ( $n$ 33). The participants had a median age (5th-95th percentile) of 59 years (46-71 years) and a median BMI (5th-95th percentile) of $26 \mathrm{~kg} / \mathrm{m}^{2}\left(21-34 \mathrm{~kg} / \mathrm{m}^{2}\right)$. Blood plasma samples were drawn in 1993-2001, and $28 \%$ of the participants were fasting when the blood samples were drawn (Table 1).

Plasma total AR concentrations varied substantially between the ten countries (Fig. 1 and Table 2). A statistically significant
Table 1. Lifestyle, socio-economic and dietary characteristics of 2845 participants from the European Prospective Investigation into Cancer and Nutrition (EPIC)

(Median values and 5th (P5)-95th percentiles (P95); number of participants and percentages)

\begin{tabular}{|c|c|c|}
\hline \multirow[b]{2}{*}{ Characteristics } & \multicolumn{2}{|c|}{$\begin{array}{l}\text { All participants } \\
\text { ( } n \text { 2845) }\end{array}$} \\
\hline & $n$ & $\%$ \\
\hline \multicolumn{3}{|l|}{ Age at blood collection (years) } \\
\hline Median & \multicolumn{2}{|c|}{59} \\
\hline P5-P95 & \multicolumn{2}{|c|}{$46-71$} \\
\hline Men & 1371 & 48 \\
\hline Women & 1474 & 52 \\
\hline \multicolumn{3}{|l|}{ BMI $\left(\mathrm{kg} / \mathrm{m}^{2}\right)$} \\
\hline Median & \multicolumn{2}{|c|}{26} \\
\hline P5-P95 & \multicolumn{2}{|c|}{$21-34$} \\
\hline \multicolumn{3}{|l|}{ Country } \\
\hline Denmark & 732 & 26 \\
\hline France & 58 & 2 \\
\hline Germany & 328 & 12 \\
\hline Greece & 80 & 3 \\
\hline Italy & 381 & 13 \\
\hline The Netherlands & 302 & 11 \\
\hline Norway & 33 & 1 \\
\hline Spain & 326 & 11 \\
\hline Sweden & 162 & 6 \\
\hline UK general population & 382 & 13 \\
\hline UK 'health conscious' & 61 & 2 \\
\hline \multicolumn{3}{|l|}{ Energy $(\mathrm{kcal} / \mathrm{d})$} \\
\hline Median & \multicolumn{2}{|c|}{2055} \\
\hline P5-P95 & \multicolumn{2}{|c|}{$1226-3290$} \\
\hline \multicolumn{3}{|l|}{ Energy $(\mathrm{kJ} / \mathrm{d})$} \\
\hline Median & \multicolumn{2}{|c|}{8598} \\
\hline P5-P95 & \multicolumn{2}{|c|}{$5130-13765$} \\
\hline \multicolumn{3}{|l|}{ Fasting status } \\
\hline Non-fasting $(<3 \mathrm{~h}$ since the last meal) & 1354 & 48 \\
\hline In between fasting ( $3-6 \mathrm{~h}$ since the last meal) & 621 & 22 \\
\hline Fasting ( $>6 \mathrm{~h}$ since the last meal) & 810 & 28 \\
\hline Unknown & 60 & 2 \\
\hline \multicolumn{3}{|l|}{ Cereal and cereal products (g/d) } \\
\hline Median & \multicolumn{2}{|c|}{194} \\
\hline P5-P95 & \multicolumn{2}{|c|}{$77-424$} \\
\hline \multicolumn{3}{|l|}{ Breakfast cereals $(\mathrm{g} / \mathrm{d})$} \\
\hline Median & \multirow{2}{*}{\multicolumn{2}{|c|}{$\begin{array}{c}0 \\
0-104\end{array}$}} \\
\hline P5-P95 & & \\
\hline \multicolumn{3}{|l|}{ Bread and crisp bread (g/d) } \\
\hline Median & & \\
\hline P5-P95 & 33 & \\
\hline Bread, non-white (g/d) & & \\
\hline Median & & \\
\hline P5-P95 & & \\
\hline Dietary fibre & & \\
\hline Median & & \\
\hline P5-P95 & & \\
\hline Cereal fibre & & \\
\hline Median & & \\
\hline P5-P95 & & \\
\hline
\end{tabular}

difference in plasma total AR concentrations was found between the countries $(P<0 \cdot 001)$. When not taking fasting status into account (Fig. 1(a) and Table 2), plasma total AR concentrations were highest in the Danish and UK cohorts, with geometric mean concentrations being $63 \mathrm{nmol} / 1$ in the Danish cohort and 70 and $63 \mathrm{nmol} / 1$ in the UK cohorts representing 'health-conscious' and the general population, respectively. A statistically significant difference was found in plasma total AR concentrations by fasting status $(P<0 \cdot 001)$. 
(a)

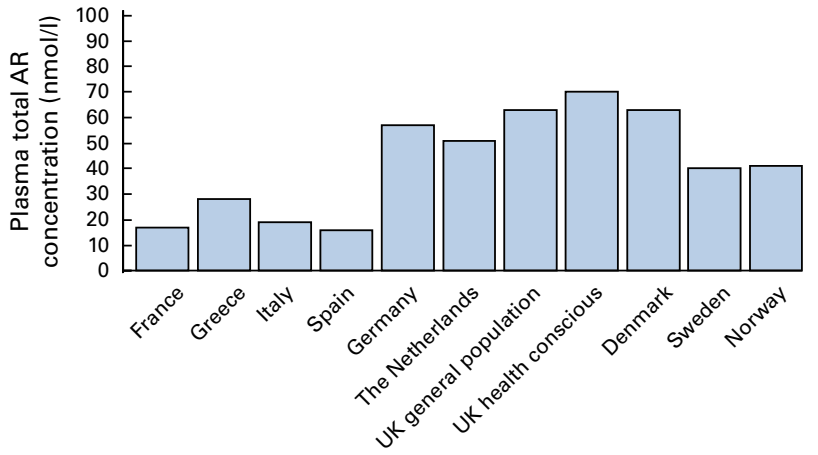

(c)

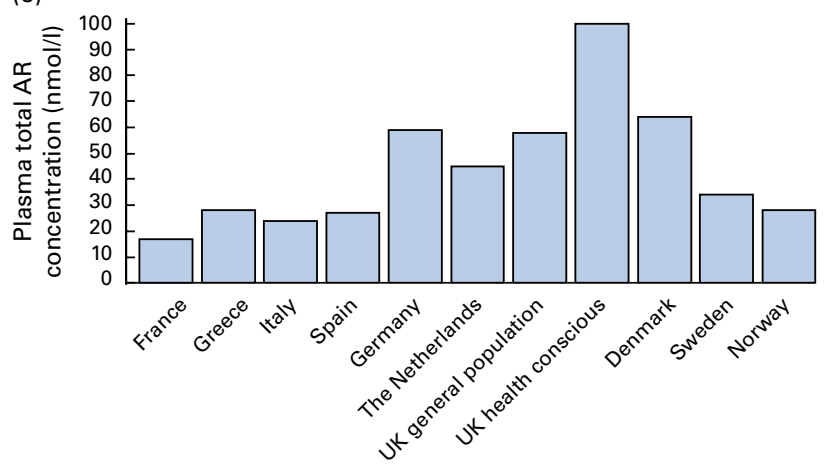

(b)

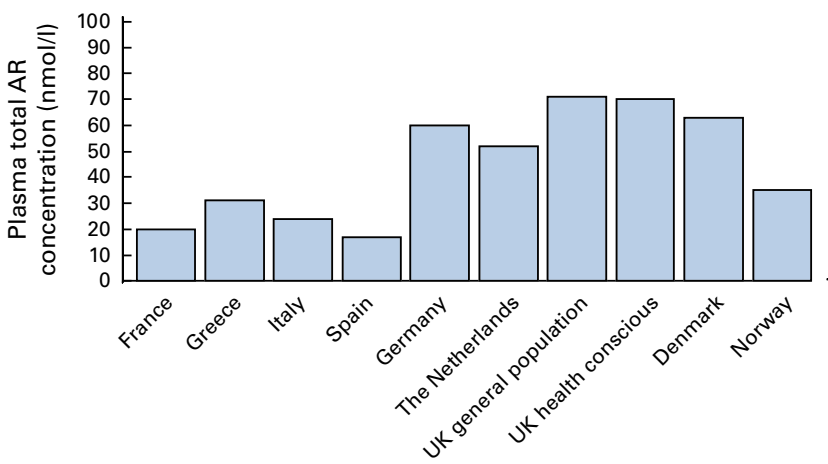

(d)

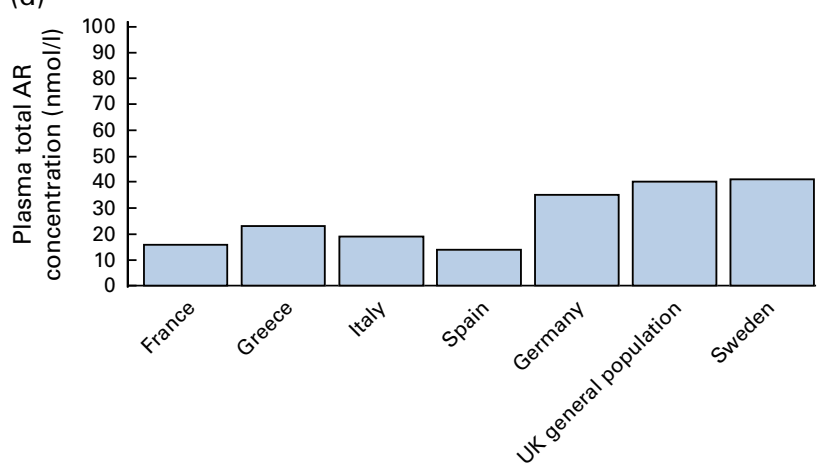

Fig. 1. Geometric mean plasma total alkylresorcinol (AR) concentrations (nmol/l) by country (by centre for the UK) in 2845 participants from the European Prospective Investigation into Cancer and Nutrition (EPIC): (a) for all participants ( $n$ 2845); (b) non-fasting: for participants who had their plasma samples drawn at $<3 \mathrm{~h}$ since the last meal $(n 1354)$, (c) in between fasting: for participants who had their blood samples drawn at 3-6h since the last meal $(n 621)$, (d) fasting: for participants who had their blood samples drawn at more than $6 \mathrm{~h}$ since the last meal $(n 792)$. A total of sixty participants had unknown fasting status, and eighteen participants were part of the group consisting of less than ten participants. Therefore, these were only included in the analyses where fasting status was not taken into account (a). (A colour version of this figure can be found online at http://www.journals.cambridge.org/bjn)

Among the participants who were fasting when the blood samples were drawn, the highest mean total AR concentrations were found in Swedish men $(49 \mathrm{nmol} / \mathrm{l})$, whereas low concentrations were found in participants from the Mediterranean countries in general (mean AR concentrations: fasting $<23 \mathrm{nmol} / 1$; Fig. 1(d) and Table 3). However, a mean total AR concentration of $37 \mathrm{nmol} / 1$ was found in Greek women, but this value was based on only ten participants. No difference in mean total AR concentrations was found between men and women, except in the Italian, Spanish, Danish and Swedish cohorts, where men had higher concentrations. Mean plasma total AR concentrations did not seem to be significantly different depending on age (data not shown).

A high median C17:0/C21:0 ratio $(\geq 0 \cdot 30)$ was observed in the German, Danish and Swedish cohorts, indicating that a proportionally higher amount of rye was being consumed by the participants from these countries (Table 2). In the Greek, Italian, Dutch and British cohorts, a low median ratio was found $(<0 \cdot 20)$, indicating that the AR-containing wholegrain diet in these countries is dominated by wheat. No difference in the mean $\mathrm{C} 17: 0 / \mathrm{C} 21: 0$ ratio was found depending on sex, except in the German and Danish cohorts, where women had higher statistically significant ratios. The ratio differed according to fasting status $(P<0 \cdot 001)$; in general, the ratio was higher in fasting samples (Table 3 ).

Cereal fibre intake was correlated with plasma total AR concentrations (Table 4). When stratifying by country, a statistically significant positive correlation was found (partial Pearson's $r$ 0.12-0.35), except for France, Greece, UK 'health conscious' and Norway. For Sweden, a statistically significant positive correlation was observed only for the crude Pearson correlation and not when corrected for sex and fasting status. The overall partial correlation for all participants was 0.22 for cereal fibre $(P<0 \cdot 001)$. Overall, the correlations were similar for men and women (data not shown).

\section{Discussion}

Large variations in plasma $\mathrm{AR}$ concentrations were found across Western Europe, with 2-3-fold higher concentrations being observed in Central Europe and in Scandinavia than in the Mediterranean countries.

Several weaknesses should be considered when interpreting the results of the present study. First, samples analysed in the present study were selected from a nested case-control study on colorectal cancer among participants in the EPIC study and therefore the number of participants per country and the fasting status were different within and between the countries. In some of the included countries, e.g. Norway, the number of participants included was small ( $n$ 33). Therefore, especially these results should be interpreted with care. Only a single sample was available from each participant. However, the medium- to long-term reproducibility has been shown to be modest to good for fasting samples 
Table 2. Cereal fibre intake, percentage of cereal fibre in total dietary fibre, plasma alkylresorcinol (AR) concentrations (total, C17:0, C19:0, C21:0, C23:0 and C25:0) and C17:0/C21:0 ratios by country (by centre for the UK) of 2845 participants from the European Prospective Investigation into Cancer and Nutrition (EPIC)

(Mean values and standard deviations)

\begin{tabular}{|c|c|c|c|c|c|c|c|c|c|c|c|c|c|c|c|c|c|c|c|}
\hline \multirow[b]{3}{*}{ Country } & \multirow[b]{3}{*}{$n$} & \multicolumn{4}{|c|}{ Dietary fibre } & \multicolumn{14}{|c|}{ Plasma AR concentration (nmol/l) } \\
\hline & & \multicolumn{2}{|c|}{$\begin{array}{l}\text { Cereal fibre } \\
\text { intake }(g / d)\end{array}$} & \multicolumn{2}{|c|}{$\begin{array}{c}\text { Cereal fibre in } \\
\text { total } \\
\text { dietary fibre (\%) }\end{array}$} & \multicolumn{2}{|c|}{ Total } & \multicolumn{2}{|c|}{ C17:0 } & \multicolumn{2}{|c|}{ C19:0 } & \multicolumn{2}{|c|}{$\mathrm{C} 21: 0$} & \multicolumn{2}{|c|}{$\mathrm{C} 23: 0$} & \multicolumn{2}{|c|}{$\mathrm{C} 25: 0$} & \multicolumn{2}{|c|}{$\begin{array}{c}\mathrm{C} 17: 0 / \mathrm{C} 21: 0 \\
\text { ratio }\end{array}$} \\
\hline & & Mean & SD & Mean & SD & Mean* & SD & Mean* & SD & Mean* & SD & Mean* & SD & Mean* & SD & Mean* & SD & Mean* & SD \\
\hline France† & 58 & $6 \cdot 2$ & $3 \cdot 2$ & 27 & 12 & 17 & 2 & 2 & 2 & 3 & 2 & 6 & 2 & 3 & 2 & 1 & 17 & 0.27 & 2 \\
\hline Greece & 80 & 6.5 & $2 \cdot 7$ & 32 & 11 & 28 & 2 & 1 & 3 & 5 & 2 & 11 & 2 & 4 & 7 & 4 & 2 & $0 \cdot 13$ & 3 \\
\hline Men & 38 & $7 \cdot 2$ & $2 \cdot 6$ & 34 & 10 & 26 & 2 & 1 & 2 & 4 & 2 & 11 & 2 & 4 & 2 & 4 & 2 & $0 \cdot 12$ & 3 \\
\hline Women & 42 & 5.9 & $2 \cdot 6$ & 31 & 12 & 29 & 2 & 2 & 3 & 5 & 2 & 11 & 2 & 4 & 12 & 4 & 2 & $0 \cdot 15$ & 3 \\
\hline Italy & 381 & $7 \cdot 8$ & 4.0 & 36 & 13 & 19 & 2 & 1 & 4 & 3 & 3 & 7 & 3 & 3 & 3 & 3 & 8 & $0 \cdot 17$ & 4 \\
\hline Men & 154 & $9 \cdot 3$ & 4.5 & 41 & 14 & 24 & 3 & 1 & 3 & 3 & 2 & 9 & 3 & 4 & 5 & 5 & 3 & 0.15 & 3 \\
\hline Women & 227 & $6 \cdot 7$ & 3.3 & 33 & 12 & 17 & 2 & 1 & 5 & 3 & 4 & 6 & 2 & 3 & 2 & 2 & 13 & $0 \cdot 19$ & 5 \\
\hline Spain & 326 & 6.5 & 3.4 & 26 & 12 & 16 & 2 & 1 & 4 & 3 & 3 & 5 & 2 & 2 & 11 & 2 & 6 & 0.22 & 4 \\
\hline Men & 192 & $7 \cdot 4$ & 3.4 & 28 & 11 & 17 & 2 & 1 & 4 & 3 & 3 & 6 & 2 & 2 & 10 & 2 & 8 & 0.21 & 4 \\
\hline Women & 134 & $5 \cdot 3$ & $2 \cdot 9$ & 24 & 12 & 14 & 2 & 1 & 5 & 2 & 2 & 5 & 2 & 1 & 14 & 2 & 4 & 0.23 & 5 \\
\hline Germany & 328 & $9 \cdot 7$ & 4.4 & 44 & 13 & 57 & 3 & 5 & 2 & 14 & 3 & 18 & 3 & 8 & 3 & 10 & 3 & 0.29 & 2 \\
\hline Men & 214 & $10 \cdot 0$ & 4.5 & 45 & 13 & 60 & 3 & 5 & 2 & 15 & 3 & 19 & 3 & 9 & 3 & 10 & 3 & 0.27 & 2 \\
\hline Women & 114 & 9.1 & 4.3 & 41 & 12 & 51 & 2 & 5 & 2 & 12 & 3 & 15 & 2 & 7 & 2 & 9 & 3 & 0.33 & 2 \\
\hline The Netherlands & 302 & $7 \cdot 3$ & $3 \cdot 3$ & 33 & 11 & 51 & 3 & 3 & 2 & 12 & 3 & 20 & 3 & 6 & 4 & 5 & 6 & $0 \cdot 14$ & 2 \\
\hline Men & 48 & $9 \cdot 6$ & 4.4 & 38 & 11 & 44 & 3 & 3 & 2 & 11 & 3 & 18 & 3 & 4 & 11 & 4 & 11 & 0.17 & 3 \\
\hline Women & 254 & $6 \cdot 9$ & 2.9 & 32 & 10 & 52 & 3 & 3 & 2 & 13 & 3 & 21 & 3 & 7 & 3 & 6 & 5 & $0 \cdot 14$ & 2 \\
\hline UK general population & 382 & $7 \cdot 3$ & $5 \cdot 0$ & 31 & 13 & 63 & 3 & 2 & 3 & 14 & 5 & 27 & 5 & 8 & 4 & 7 & 5 & 0.09 & 2 \\
\hline Men & 206 & $7 \cdot 3$ & $5 \cdot 1$ & 32 & 13 & 62 & 3 & 2 & 2 & 14 & 3 & 27 & 4 & 9 & 3 & 7 & 5 & 0.09 & 2 \\
\hline Women & 176 & $7 \cdot 3$ & 4.9 & 31 & 13 & 64 & 3 & 2 & 4 & 13 & 6 & 26 & 6 & 8 & 5 & 6 & 5 & 0.09 & 2 \\
\hline UK 'health conscious' & 61 & $9 \cdot 7$ & $5 \cdot 4$ & 34 & 13 & 70 & 3 & 3 & 2 & 16 & 3 & 31 & 3 & 10 & 3 & 8 & 3 & $0 \cdot 10$ & 2 \\
\hline Men & 20 & $12 \cdot 9$ & 6.5 & 41 & 14 & 140 & 2 & 5 & 2 & 35 & 3 & 65 & 3 & 17 & 2 & 14 & 3 & 0.07 & 2 \\
\hline Women & 41 & $8 \cdot 1$ & 4.0 & 31 & 11 & 50 & 2 & 2 & 2 & 11 & 3 & 21 & 3 & 7 & 2 & 6 & 2 & $0 \cdot 11$ & 2 \\
\hline Denmark & 732 & $13 \cdot 4$ & $5 \cdot 8$ & 53 & 13 & 63 & 2 & 7 & 2 & 15 & 3 & 18 & 2 & 8 & 4 & 11 & 4 & 0.37 & 2 \\
\hline Men & 403 & $14 \cdot 2$ & 5.9 & 56 & 13 & 68 & 2 & 7 & 2 & 17 & 3 & 20 & 3 & 9 & 4 & 12 & 3 & 0.35 & 2 \\
\hline Women & 329 & $12 \cdot 4$ & 5.5 & 51 & 13 & 57 & 2 & 7 & 2 & 13 & 4 & 16 & 2 & 7 & 5 & 10 & 5 & 0.40 & 2 \\
\hline Sweden & 162 & $10 \cdot 6$ & $4 \cdot 6$ & 53 & 14 & 40 & 2 & 5 & 2 & 8 & 5 & 11 & 2 & 5 & 4 & 8 & 5 & 0.43 & 2 \\
\hline Men & 96 & $12 \cdot 0$ & 4.6 & 57 & 14 & 48 & 2 & 5 & 2 & 11 & 2 & 13 & 2 & 7 & 2 & 10 & 2 & 0.40 & 2 \\
\hline Women & 66 & 8.5 & 3.6 & 47 & 12 & 30 & 2 & 4 & 2 & 5 & 8 & 8 & 2 & 3 & 8 & 5 & 8 & 0.47 & 2 \\
\hline Norway† & 33 & $9 \cdot 6$ & 4.0 & 46 & 12 & 41 & 3 & 4 & 3 & 11 & 3 & 14 & 3 & 5 & 3 & 6 & 3 & 0.26 & 2 \\
\hline
\end{tabular}

*Geometric mean.

tCohort consists of only women. 
Table 3. Plasma total alkylresorcinol (AR) concentrations and AR homologue $\mathrm{C} 17: 0 / \mathrm{C} 21: 0$ ratio by country (centre for the UK) and fasting status of 2845 participants from the European Prospective Investigation into Cancer and Nutrition (EPIC)

(Mean values and standard deviations)

\begin{tabular}{|c|c|c|c|c|c|c|c|c|c|c|c|c|c|c|c|c|}
\hline \multirow[b]{4}{*}{ Country } & \multirow[b]{4}{*}{$N$ (total) } & \multicolumn{15}{|c|}{ Total AR concentration (nmol/l) } \\
\hline & & \multicolumn{5}{|c|}{ Non-fasting $(<3 \mathrm{~h}$ since the last meal) } & \multicolumn{5}{|c|}{ In between fasting ( $3-6 \mathrm{~h}$ since the last meal) } & \multicolumn{5}{|c|}{ Fasting ( $>6 \mathrm{~h}$ since the last meal) } \\
\hline & & \multirow[b]{2}{*}{$n$} & \multicolumn{2}{|c|}{$\begin{array}{c}\text { Total AR } \\
\text { concentration } \\
\text { (nmol/l) }\end{array}$} & \multicolumn{2}{|c|}{$\begin{array}{c}\mathrm{C} 17: 0 / \mathrm{C} 21: 0 \\
\text { ratio }\end{array}$} & \multirow[b]{2}{*}{$n$} & \multicolumn{2}{|c|}{$\begin{array}{c}\text { Total AR } \\
\text { concentration } \\
\text { (nmol/l) }\end{array}$} & \multicolumn{2}{|c|}{$\begin{array}{c}\mathrm{C} 17: 0 / \mathrm{C} 21: 0 \\
\text { ratio }\end{array}$} & \multirow[b]{2}{*}{$n$} & \multicolumn{2}{|c|}{$\begin{array}{c}\text { Total AR } \\
\text { concentration } \\
\text { (nmol/l) }\end{array}$} & \multicolumn{2}{|c|}{$\begin{array}{c}\mathrm{C} 17: 0 / \mathrm{C} 21: 0 \\
\text { ratio }\end{array}$} \\
\hline & & & Mean $^{*}$ & SD & Mean $^{*}$ & SD & & Mean ${ }^{*}$ & SD & Mean ${ }^{*}$ & SD & & Mean $^{*}$ & SD & Mean* & SD \\
\hline France $\dagger$ & 58 & 10 & 20 & 2 & 0.32 & 3 & 18 & 17 & 2 & 0.24 & 3 & 30 & 16 & 2 & 0.26 & 2 \\
\hline Greece & 80 & 32 & 31 & 2 & 0.10 & 3 & 28 & 28 & 2 & 0.16 & 2 & 20 & 23 & 3 & 0.16 & 3 \\
\hline Men & 38 & 14 & 35 & 2 & 0.08 & 3 & 14 & 30 & 2 & 0.11 & 2 & 10 & 14 & 2 & 0.19 & 3 \\
\hline Women & 42 & 18 & 28 & 2 & 0.12 & 3 & 14 & 26 & 2 & 0.21 & 3 & 10 & 37 & 3 & 0.14 & 3 \\
\hline Italy & 381 & 44 & 24 & 3 & 0.20 & 3 & 10 & 24 & 2 & 0.17 & 2 & 327 & 19 & 2 & 0.17 & 4 \\
\hline Men & 154 & 28 & 24 & 3 & 0.19 & 3 & 4 & \multicolumn{2}{|c|}{$\ddagger$} & \multicolumn{2}{|c|}{$\ddagger$} & 122 & 24 & 3 & 0.14 & 3 \\
\hline Women & 227 & 16 & 23 & 3 & 0.24 & 3 & 6 & \multicolumn{2}{|c|}{$\ddagger$} & \multicolumn{2}{|c|}{$\ddagger$} & 205 & 16 & 2 & 0.18 & 5 \\
\hline Spain & 326 & 47 & 17 & 2 & 0.19 & 9 & 49 & 27 & 3 & 0.12 & 2 & 230 & 14 & 2 & 0.25 & 3 \\
\hline Men & 192 & 24 & 26 & 2 & 0.19 & 3 & 30 & 27 & 3 & 0.11 & 2 & 138 & 15 & 2 & 0.25 & 4 \\
\hline Women & 134 & 23 & 11 & 2 & 0.19 & 20 & 19 & 28 & 2 & 0.16 & 2 & 92 & 13 & 2 & 0.25 & 3 \\
\hline Germany§ & 328 & 215 & 60 & 2 & 0.28 & 2 & 82 & 59 & 3 & 0.29 & 2 & 29 & 35 & 2 & 0.37 & 2 \\
\hline Men & 214 & 135 & 65 & 3 & 0.27 & 2 & 56 & 62 & 3 & 0.27 & 2 & 21 & 36 & 2 & 0.31 & 2 \\
\hline Women & 114 & 80 & 52 & 2 & 0.31 & 2 & 26 & 55 & 3 & 0.34 & 2 & 8 & 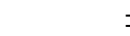 & & & \\
\hline The Netherlands§ & 302 & 268 & 52 & 3 & 0.14 & 2 & 26 & 45 & 3 & 0.16 & 2 & 2 & 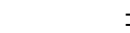 & & & \\
\hline Men & 48 & 44 & 46 & 3 & 0.16 & 3 & 2 & \multicolumn{2}{|c|}{$\ddagger$} & \multicolumn{2}{|l|}{$\ddagger$} & 2 & \multirow{2}{*}{\multicolumn{2}{|c|}{$\ddagger$}} & \multicolumn{2}{|c|}{$\ddagger$} \\
\hline Women & 254 & 224 & 53 & 3 & 0.14 & 2 & 24 & 48 & 3 & 0.16 & 2 & - & & - & & \\
\hline UK general population§ & 382 & 211 & 71 & 3 & 0.09 & 2 & 134 & 58 & 3 & 0.08 & 2 & 14 & 40 & 2 & $0 \cdot 10$ & 2 \\
\hline Men & 206 & 102 & 73 & 3 & 0.09 & 2 & 85 & 57 & 3 & 0.09 & 2 & 8 & 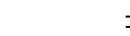 & & & \\
\hline Women & 176 & 109 & 70 & 4 & 0.09 & 2 & 49 & 59 & 3 & 0.07 & 2 & 6 & $=$ & & & \\
\hline UK 'health conscious'§ & 61 & 28 & 70 & 3 & 0.09 & 2 & 15 & 100 & 3 & $0 \cdot 10$ & 2 & 4 & 7 & & & \\
\hline Men & 20 & 7 & & & & & 4 & & & $\ddagger$ & & 2 & $z$ & & & \\
\hline Women & 41 & 21 & 49 & 2 & 0.11 & 2 & 11 & 73 & 3 & 0.12 & 2 & 2 & 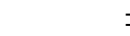 & & & \\
\hline Denmark§ & 732 & 485 & 63 & 2 & 0.36 & 2 & 233 & 64 & 2 & 0.37 & 2 & 8 & $z$ & & & \\
\hline Men & 403 & 288 & 65 & 3 & 0.35 & 2 & 101 & 79 & 2 & 0.32 & 2 & 8 & $z$ & & & \\
\hline Women & 329 & 197 & 60 & 2 & 0.38 & 2 & 132 & 54 & 2 & 0.42 & 2 & - & - & & & \\
\hline Sweden & 162 & - & & & & & 16 & 34 & 2 & 0.44 & 2 & 146 & 41 & 2 & 0.43 & 2 \\
\hline Men & 96 & - & & & & & 10 & 45 & 2 & 0.41 & 1 & 86 & 49 & 2 & 0.40 & 2 \\
\hline Women & 66 & - & & & & & 6 & & & $\ddagger$ & & 60 & 31 & 2 & 0.47 & 2 \\
\hline Norway $\ddagger \S$ & 33 & 13 & 35 & 3 & 0.29 & 2 & 10 & 28 & 3 & 0.22 & 2 & - & - & & & \\
\hline
\end{tabular}

*Geometric mean.

†Cohort consists of only women

¥ Category consists of less than ten participants and therefore results are not reported.

SInformation on fasting status was not available for sixty participants. Therefore, they were not included in the analyses stratified by fasting status (these participants were from the following countries: Germany - two participants;

the Netherlands - six participants; UK general population - twenty-two participants; UK 'health conscious' - fourteen participants; Denmark - six participants; Norway - ten participants). 
Table 4. Pearson's correlations between plasma total alkylresorcinol concentrations and cereal fibre intake by country (centre for the UK) of 2845 participants from the European Prospective Investigation into Cancer and Nutrition (EPIC)

(Pearson's correlations and $P$ values)

\begin{tabular}{|c|c|c|c|c|c|}
\hline \multirow[b]{3}{*}{ Country/centre } & \multirow[b]{3}{*}{$n$} & \multicolumn{4}{|c|}{ Cereal fibre } \\
\hline & & \multicolumn{2}{|c|}{ Crude } & \multicolumn{2}{|c|}{ Partial } \\
\hline & & $r$ & $P$ & $r$ & $P$ \\
\hline All ${ }^{*}$ & 2845 & 0.33 & $<0.001$ & 0.22 & $<0.001$ \\
\hline Non-fasting $\dagger$ & 1354 & 0.30 & $<0.001$ & 0.24 & $<0.001$ \\
\hline In between fasting $\dagger$ & 621 & 0.32 & $<0.001$ & 0.26 & $<0.001$ \\
\hline Fasting $†$ & 810 & 0.30 & $<0.001$ & 0.17 & $<0.001$ \\
\hline Missing† & 60 & 0.13 & 0.33 & 0.05 & 0.71 \\
\hline France $\neq$ & 58 & 0.00 & 0.99 & 0.00 & 0.99 \\
\hline Greeceł & 80 & 0.04 & 0.71 & 0.06 & 0.62 \\
\hline Italy $\ddagger$ & 381 & 0.18 & $<0.001$ & 0.12 & 0.02 \\
\hline Spain $\ddagger$ & 326 & 0.18 & 0.001 & 0.15 & 0.007 \\
\hline Germany $\ddagger$ & 328 & 0.23 & $<0.001$ & 0.22 & $<0.001$ \\
\hline The Netherlands $\ddagger$ & 302 & 0.24 & $<0.001$ & 0.28 & $<0.001$ \\
\hline UK general population $\ddagger$ & 382 & 0.34 & $<0.001$ & 0.35 & $<0.001$ \\
\hline UK 'health conscious' $\ddagger$ & 61 & 0.24 & 0.06 & -0.01 & 0.97 \\
\hline Denmark $\ddagger$ & 732 & 0.30 & $<0.001$ & 0.28 & $<0.001$ \\
\hline Sweden $\ddagger$ & 162 & 0.23 & 0.003 & 0.11 & 0.15 \\
\hline Norwaył & 33 & -0.04 & 0.81 & -0.05 & 0.77 \\
\hline
\end{tabular}

* Partial model corrected for fasting status, sex and country (centre for the UK).

†Partial model corrected for sex and country (centre for the UK).

$\ddagger$ Partial model corrected for fasting status and sex.

collected from different populations with a frequent intake of whole grains ${ }^{(16,17)}$. The measurement of plasma AR concentrations was carried out in singlets, and the analytical between-day variation was rather large. Furthermore, no information on whole-grain intake is available for the entire EPIC cohort. Therefore, we used cereal fibre intake as a crude proxy for whole-grain intake, although cereal fibre also included oats and other cereals, which do not contain AR. Previous studies have shown weaker correlations between cereal fibre intake and plasma total AR concentrations in plasma than for whole-grain intake, probably due to differences in the sources of cereal fibre in different populations ${ }^{(27)}$. The higher $\mathrm{C} 17: 0 / \mathrm{C} 21: 0$ ratios in non-fasting samples than in the fasting samples are in line with previous findings and suggest that the AR homologues are subject to some differences in elimination ${ }^{(15)}$. Therefore, it still needs to be clarified to what extent the $\mathrm{C} 17: 0 / \mathrm{C} 21: 0$ ratio is affected by difference in the metabolism of AR homologues. The present study included mostly middle-aged Europeans and not all subcohorts included were population based. Therefore, the results cannot be confidently extrapolated to the general Western European population.

The present study has a number of strengths. Importantly, the plasma samples of participants from all the ten included countries were assayed at the same time in the same laboratory using the same method and were randomised in different batches. This ensures that differences between the countries are not due to laboratory differences. Furthermore, a standardised food composition database was used to estimate cereal fibre intake for the entire EPIC cohort.

When not taking fasting status into account, the highest concentrations of AR were observed in the Scandinavian and Central European cohorts and the lowest concentrations in the Mediterranean region cohort. The comparably low concentrations among Swedes and Norwegians were probably because many of the Swedish and Norwegian participants were fasting when their blood samples were drawn. Surprisingly, plasma total AR concentrations in samples drawn from fasting UK participants were similar to what was found in the samples of participants from most of the Central European and Scandinavian countries. This is surprising because wholegrain intake is believed to be lower in the $\mathrm{UK}^{(28)}$ than, for instance, in Scandinavia ${ }^{(29)}$. Furthermore, calculations of AR intake from food supply data and food composition data also indicate that AR intake is lower in the UK than in Sweden ${ }^{(30)}$. There are no obvious explanations for the high concentrations observed in participants from the UK, but they are probably due to the high intakes of wheat bran or food products containing flour with a high extraction rate, but not classified as whole grains.

Few studies have reported on and compared plasma total $\mathrm{AR}$ concentrations in different populations. In an American cross-sectional study of 407 free-living older adults, the overall median concentration of AR was not mentioned, but the median fasting plasma AR concentrations were 5, 14, 27 and $62 \mathrm{nmol} / 1$ across the AR concentration quartiles ${ }^{(31)}$. This is similar to the total AR concentrations found in the plasma samples of participants from the Mediterranean region in the present study, indicating that the quantities of whole-grain wheat and rye consumed in the USA are similar to those consumed in the Mediterranean region. In one of the German subcohorts of the present study (EPIC-Potsdam), AR concentrations were measured in fasting plasma samples drawn 4 months apart in 100 participants. The geometric mean from both measurements was $49 \mathrm{nmol} / \mathrm{l}^{(16)}$. In the present study, fasting participants from EPIC-Potsdam ( $n$ 29) had a geometric mean AR concentration of $35 \mathrm{nmol} / 1$ (data not shown). In a previous study from EPIC-Denmark, AR concentrations were measured in plasma samples collected from 360 postmenopausal women who were non-fasting when the samples were drawn, and the median AR concentration was $78 \mathrm{nmol} / \mathrm{l}^{(13)}$. We found lower median total AR concentrations of $52 \mathrm{nmol} / 1$ in postmenopausal Danish women (data not shown). The difference could be due to differences in fasting status in the previous study and the present study. Laboratory analyses of both the earlier studies were conducted in the same laboratory where those of the present study were carried out. Additionally, in a Danish intervention study of seventy-nine overweight or obese women, the baseline geometric mean plasma total AR concentration was $50 \mathrm{nmol} / \mathrm{l}^{(26)}$, and a recent Nordic intervention study has found baseline median fasting AR concentrations of 59 and $56 \mathrm{nmol} / 1$ for Swedes from Lund and Uppsala, respectively, and $67 \mathrm{nmol} / 1$ for Danes from Aarhus ${ }^{(32)}$. The findings of the mentioned previous studies are overall similar to those of the present study. These findings indicate a potential of using fasting plasma AR concentrations to enable comparison between studies and populations. Information on whole-grain intake in Europe is scarce, and differences in the definitions of whole grains and variation in the products consumed complicate comparison of whole-grain intake. Therefore, AR might be a 
good complementary tool for the assessment of wholegrain intake.

Few studies have used the ratio between two of the AR homologues (C17:0 and $\mathrm{C} 21: 0)$ to indicate whether the whole-grain diet is dominated by whole-grain wheat or whole-grain rye. As expected, we found that the whole-grain diet of the Greek, Italian, Dutch and UK participants was dominated by wheat, as indicated by a low C17:0/C21:0 ratio, whereas the ratio was higher for the German, Danish and Swedish participants, indicating a higher whole-grain rye intake. These results are in line with those of a descriptive study on the intake of different whole-grain cereals in the Scandinavian part of the present study. In that study, it was found that rye intake constituted about $70 \%$ of the wholegrain intake in Denmark, $55 \%$ in Sweden and 20\% in Norway $^{(29)}$. It is surprising that the $\mathrm{C} 17: 0 / \mathrm{C} 21: 0$ ratio is higher among the Swedish participants than among the Danish participants in the present study $(0.43 v .0 .37)$. Among the whole grains, wheat is primarily consumed in Norway, whereas rye is consumed in larger proportions in Sweden and Denmark $^{(29)}$. As expected, the C17:0/C21:0 ratio was lower among the Norwegian participants $(0 \cdot 27)$. In the earlier mentioned Danish intervention study, a C17:0/C21:0 ratio of $0 \cdot 13$ was observed at baseline ${ }^{(26)}$, which is much lower than that found in the present study. According to the Danish national dietary surveys, the rye bread intake did not change between baseline of the present study and $2004^{(33)}$. The difference might be due to the participants included in the intervention study being overweight and obese ${ }^{(26)}$ and therefore having different dietary habits and lower rye bread intake. Previous observational studies conducted in Finnish, Swiss and Danish populations have reported $\mathrm{C} 17: 0 / \mathrm{C} 21: 0$ ratios. In these studies, the $\mathrm{C} 17: 0 / \mathrm{C} 21: 0$ ratio for Danes (EPIC-Denmark) was $0 \cdot 40$, for Finns 0.63 , and for Swiss $0 \cdot 17^{(34)}$. As the intake of rye is even higher in Finland than in Denmark, it is expected that the ratio would also be higher in Finland than in Denmark ${ }^{(35)}$, and the results obtained for the Danish populations are similar to the findings of the present study. The results reported in the present study support the utility of the $\mathrm{C} 17: 0 / \mathrm{C} 21: 0$ ratio for comparison of types of whole grains consumed in different populations.

In the present study, cereal fibre intake was found to be moderately or weakly correlated with plasma total AR concentrations. Overall, the correlations were higher in countries with a wide range of plasma total $\mathrm{AR}$ concentrations, i.e. Central Europe and Scandinavia, where the majority of the correlations were $>0 \cdot 25$. The highest correlations were found in the UK general population, where the plasma total AR concentrations were also highest. The correlations are similar to what has been reported previously ${ }^{(32,34)}$. In general, stronger correlations have previously been found between whole-grain wheat and rye intake and AR concentrations than between cereal fibre intake and AR concentrations. This is expected, because cereals other than wheat and rye as well as refined grains contribute to cereal fibre intake, but not to AR intake and plasma AR concentrations.

The present study demonstrates large variations in plasma AR concentrations in the ten countries included in the EPIC study, which seems to be largely due to differences in whole-grain wheat and rye intake between the countries. The plasma total AR concentrations were higher in Central Europe and Scandinavia and lower in the Mediterranean region. Using the $\mathrm{AR} \mathrm{C} 17: 0 / \mathrm{C} 21: 0$ ratio, it was found that the Danish, German and Swedish participants consumed rye in considerable amounts, whereas wheat was mostly consumed in the other seven European countries included in the study. We found modest/weak correlations with cereal fibre intake estimated from the FFQ.

\section{Acknowledgements}

The authors thank data managers Katja Boll, Nick Martinussen and Bertrand Hemon for assistance with data preparation and also Jytte Fogh Larsen for her administrative assistance. The authors also thank Ola Andersson and Janicka Nilsson for their excellent work on the laboratory analyses.

The present study was funded by Wereld Kanker Onderzoek Fonds (WCRF NL) grant no 2011/436, as part of the WCRF International grant programme and NordForsk (Centre of Excellence programme HELGA (070015)).

The coordination of EPIC is financially supported by the European Commission (DG-SANCO) and the International Agency for Research on Cancer. The national cohorts are supported by Danish Cancer Society (Denmark); Ligue Contre le Cancer, Institut Gustave Roussy, Mutuelle Générale de l'Education Nationale, Institut National de la Santé et de la Recherche Médicale (INSERM) (France); German Cancer Aid, German Cancer Research Center (DKFZ), Federal Ministry of Education and Research (Germany); the Hellenic Health Foundation (Greece); Associazione Italiana per la Ricerca sul Cancro-AIRC-Milan and National Research Council (Italy); Dutch Ministry of Public Health, Welfare and Sports (VWS), Netherlands Cancer Registry (NKR), LK Research Funds, Dutch Prevention Funds, Dutch ZON (Zorg Onderzoek Nederland), World Cancer Research Fund (WCRF), Statistics Netherlands (The Netherlands); ERC-2009-AdG 232997, the Norwegian Research Council, Extrastiftelsen Helse og Rehabiliering med Extra-midler (Norway); Health Research Fund (FIS), Regional Governments of Andalucía, Asturias, Basque Country, Murcia (no. 6236) and Navarra, ISCIII RETIC (RD06/0020) (Spain); Swedish Cancer Society, Swedish Scientific Council and Regional Government of Skåne and Västerbotten (Sweden); Cancer Research UK, Medical Research Council (UK)

The authors' contributions are as follows: C. K., A. O., H. B. B., R. L. and A. T. designed and conducted the research; C. K. coordinated and R. L. supervised the laboratory analyses; C. K. and J. C. analysed the data. All authors were involved in data interpretation and manuscript preparation.

The authors declare no conflicts of interest.

\section{References}

1. Lillioja S, Neal AL, Tapsell L, et al. (2013) Whole grains, type 2 diabetes, coronary heart disease, and hypertension: links to the aleurone preferred over indigestible fiber. Biofactors 39, 242-258. 
2. Borneo R \& Leon AE (2012) Whole grain cereals: functional components and health benefits. Food Funct 3, 110-119.

3. WCRF/AICR (2011) Continuous Update Project Interim Report Summary. Food, nutrition, physical activity, and the prevention of colorectal cancer. http://www.wcrf.org/ cancer_research/cup/key_findings/colorectal_cancer.php (accessed February 2013).

4. Aune D, Chan DS, Lau R, et al. (2011) Dietary fibre, whole grains, and risk of colorectal cancer: systematic review and dose-response meta-analysis of prospective studies. BMJ 343, d6617.

5. WCRF/AICR (2007) Food, Nutrition, Physical Activity, and the Prevention of Cancer - A Global Perspective. Washington, DC: AICR.

6. Freedman LS, Schatzkin A, Midthune D, et al. (2011) Dealing with dietary measurement error in nutritional cohort studies. J Natl Cancer Inst 103, 1086-1092.

7. van Dam RM \& Hu FB (2008) Are alkylresorcinols accurate biomarkers for whole grain intake? Am J Clin Nutr 87, 797-798.

8. Frolich W \& Aman P (2010) Whole grain for whom and why? Food Nutr Res $\mathbf{5 4}$ (epublication 12 March 2010).

9. Landberg R, Kamal-Eldin A, Andersson A, et al. (2008) Alkylresorcinols as biomarkers of whole-grain wheat and rye intake: plasma concentration and intake estimated from dietary records. Am J Clin Nutr 87, 832-838.

10. Ross AB \& Kochhar S (2009) Rapid and sensitive analysis of alkylresorcinols from cereal grains and products using HPLC-Coularray-based electrochemical detection. I Agric Food Chem 57, 5187-5193.

11. Ross AB, Kamal-Eldin A, Lundin EA, et al. (2003) Cereal alkylresorcinols are absorbed by humans. J Nutr 133 2222-2224.

12. Landberg R, Kamal-Eldin A, Andersson SO, et al. (2009) Reproducibility of plasma alkylresorcinols during a 6-week rye intervention study in men with prostate cancer. $J$ Nutr 139, 975-980.

13. Landberg R, Kamal-Eldin A, Aman P, et al. (2011) Determinants of plasma alkylresorcinol concentration in Danish post-menopausal women. Eur J Clin Nutr 65, 94-101.

14. Ross AB, Pineau N, Kochhar S, et al. (2009) Validation of a FFQ for estimating whole-grain cereal food intake. $\mathrm{BrJ}$ Nutr 102, 1547-1551.

15. Landberg R, Linko AM, Kamal-Eldin A, et al. (2006) Human plasma kinetics and relative bioavailability of alkylresorcinols after intake of rye bran. J Nutr 136, 2760-2765.

16. Montonen J, Landberg R, Kamal-Eldin A, et al. (2010) Reliability of fasting plasma alkylresorcinol concentrations measured 4 months apart. Eur J Clin Nutr 64, 698-703.

17. Landberg R, Aman P, Hallmans G, et al. (2013) Long-term reproducibility of plasma alkylresorcinols as biomarkers of whole-grain wheat and rye intake within Northern Sweden Health and Disease Study Cohort. Eur J Clin Nutr 67, 259-263.

18. Chen Y, Ross AB, Aman P, et al. (2004) Alkylresorcinols as markers of whole grain wheat and rye in cereal products. J Agric Food Chem 52, 8242-8246.

19. Linko AM, Juntunen KS, Mykkanen HM, et al. (2005) Wholegrain rye bread consumption by women correlates with plasma alkylresorcinols and increases their concentration compared with low-fiber wheat bread. J Nutr 135, 580-583.
20. Landberg R, Aman P, Friberg LE, et al. (2009) Dose response of whole-grain biomarkers: alkylresorcinols in human plasma and their metabolites in urine in relation to intake. Am J Clin Nutr 89, 290-296.

21. Riboli E, Hunt KJ, Slimani N, et al. (2002) European Prospective Investigation into Cancer and Nutrition (EPIC): study populations and data collection. Public Health Nutr 5, 1113-1124.

22. Slimani N, Deharveng G, Unwin I, et al. (2007) The EPIC nutrient database project (ENDB): a first attempt to standardize nutrient databases across the 10 European countries participating in the EPIC study. Eur J Clin Nutr 61, 1037-1056.

23. DeVries JW \& Rader JI (2005) Historical perspective as a guide for identifying and developing applicable methods for dietary fiber. J AOAC Int 88, 1349-1366.

24. Englyst HN, Quigley ME, Hudson GJ, et al. (1992) Determination of dietary fibre as non-starch polysaccharides by gas-liquid chromatography. Analyst 117, 1707-1714.

25. Landberg R, Aman P \& Kamal-Eldin A (2009) A rapid gas chromatography-mass spectrometry method for quantification of alkylresorcinols in human plasma. Anal Biochem 385, 7-12.

26. Kristensen M, Toubro S, Jensen MG, et al. (2012) Whole grain compared with refined wheat decreases the percentage of body fat following a 12-week, energy-restricted dietary intervention in postmenopausal women. $J$ Nutr $\mathbf{1 4 2}$, 710-716.

27. Andersson A, Marklund M, Diana M, et al. (2011) Plasma alkylresorcinol concentrations correlate with whole grain wheat and rye intake and show moderate reproducibility over a 2- to 3-month period in free-living Swedish adults. J Nutr 141, 1712-1718.

28. Thane CW, Jones AR, Stephen AM, et al. (2007) Comparative whole-grain intake of British adults in 1986-7 and 2000-1. Br J Nutr 97, 987-992.

29. Kyro C, Skeie G, Dragsted LO, et al. (2012) Intake of whole grain in Scandinavia: intake, sources and compliance with new national recommendations. Scand J Public Health 40, $76-84$.

30. Ross AB, Becker W, Chen Y, et al. (2005) Intake of alkylresorcinols from wheat and rye in the United Kingdom and Sweden. Br J Nutr 94, 496-499.

31. Ma J, Ross AB, Shea MK, et al. (2012) Plasma alkylresorcinols, biomarkers of whole-grain intake, are related to lower BMI in older adults. J Nutr 142, 1859-1864.

32. Magnusdottir OK, Landberg R, Gunnarsdottir I, et al. (2013) Plasma alkylresorcinols reflect important whole-grain components of a healthy Nordic diet. J Nutr 143, 1383-1390.

33. DTU Food - The National Food Institute (Denmark) (2008) Fuldkorn - Definition og vidensgrundlag for anbefaling af fuldkornsindtag i Danmark (Wholegrain - definition and scientific background for recommendations). http://www. fuldkorn.dk/files/Rapporter/Fuldkorn\%20definition $\% 20 \mathrm{og} \%$ 20vidensgrundlag.pdf (accessed January 2013).

34. Ross AB (2012) Present status and perspectives on the use of alkylresorcinols as biomarkers of wholegrain wheat and rye intake. J Nutr Metab 2012, 462967.

35. Nurmi T, Mursu J, Penalvo JL, et al. (2010) Dietary intake and urinary excretion of lignans in Finnish men. BrJ Nutr 103, $677-685$. 